Article

\title{
An Enhanced Mapping Function with Ionospheric Varying Height
}

\author{
Yan Xiang *(-) and Yang Gao \\ Department of Geomatics Engineering, University of Calgary, 2500 University Drive NW, \\ Calagry T2N 1N4, Canada; ygao@ucalgary.ca \\ * Correspondence: yan.xiang@ucalgary.ca
}

Received: 23 May 2019; Accepted: 1 June 2019; Published: 25 June 2019

check for updates

\begin{abstract}
Mapping function (MF) converts the line-of-sight slant total electron content (STEC) into the vertical total electron content (VTEC), and vice versa. In an MF, an essential parameter is the ionospheric effective height. However, the inhomogeneous ionosphere makes this height vary spatially and temporally, meaning it is not a global constant. In the paper, we review several mapping functions and propose a mapping function that utilizes the ionospheric varying height (IVH). We investigate impacts of the IVH on mapping errors and on the ionospheric modeling, as well as on the satellite and receiver differential code biases (DCBs). Our analysis results indicate that the mapping errors using IVH are smaller than those from the fixed height of $450 \mathrm{~km}$. The integral height achieves smaller mapping errors than using a fixed height of $450 \mathrm{~km}$, an improvement of about $8 \%$ when compared with the fixed height of $450 \mathrm{~km}$. And 35\% smaller mapping errors were found using $\mathrm{HmF} 2$ at the lower latitude. Also, the effects of IVH on the satellite DCBs are about $0.1 \mathrm{~ns}$, and larger impacts on the receiver DCBs at $1.0 \mathrm{~ns}$.
\end{abstract}

Keywords: ionospheric varying height (IVH); mapping function (MF); mapping errors; total electron content (TEC); ionospheric modeling; differential code bias (DCB)

\section{Introduction}

The ionosphere is dispersive, dynamic, inhomogeneous, and is the ionized part of the upper atmosphere charged by solar radiation. To monitor the ionosphere, dual-frequency observations from the global navigation satellite systems (GNSS) have been an efficient and cost effective tool [1]. The crucial ionospheric parameter is total electron content (TEC). It is proportional to ionospheric delays. However, both satellite and receiver differential code biases (DCBs) adversely distort the GNSS-derived ionospheric observables for obtaining absolute TEC. To separate the DCBs from the TEC, ionospheric modeling is necessary [2-4].

For ionospheric modeling, a mapping function (MF) is required to convert the line-of-sight slant TEC (STEC) into the vertical TEC (VTEC), and vice versa. The ratio of STEC to VTEC gives the MF. This ratio is based on the assumption of the single-layer model (SLM): all electrons are condensed into an infinitesimal thickness layer at a single-layer height. The MF depends on the elevation and on the ionospheric effective height of the SLM, the latter of which is the focus of our research.

In investigating the role the effective height of the SLM plays in MF, Lanyi and Roth [5] proposed that this height has to be established between 350 and $400 \mathrm{~km}$, at an average altitude of maximum electron density. Hernández-Pajares et al. [6] derived the height from worldwide distributed GPS data, ranging from 350 to $650 \mathrm{~km}$. Brunini et al. [7] investigated how the single-layer height between 300 and $550 \mathrm{~km}$ affected VTEC and DCB estimates. They concluded that a unique height did not achieve zero conversion errors and that solar activities, time of year, and latitude affected the errors. 
Wang et al. [8] demonstrated that every $100 \mathrm{~km}$ of height increase resulted in a difference of about 1.8 TEC unit (TECU) in VTEC.

To estimate the effective height of the SLM, Birch et al. [9] proposed an inverse method that uses overhead observations to calculate the inclination rates of the simultaneous vertical and slant observations. However, the method cannot reach a consistent height at the different time, location, and levels of solar activity. Nava et al. [10] minimized mapping errors to determine the height using the coinciding pierce point (CPP) method by defining two ionospheric pierce points within $0.2^{\circ}$ latitude. At middle latitudes, the mapping errors were 5 TECU in quiet geomagnetic periods and as high as 60 TECU in disturbed periods. They recommended an effective height of $400 \mathrm{~km}$ for the quiet periods and $500 \mathrm{~km}$ for the disturbed periods. To make their calculations, Zhao and Zhou [11] applied the method of minimizing the satellite DCBs when compared with products from Center for Orbit Determination in Europe (CODE). They found the derived height had an N-shaped relationship with latitudes.

Nevertheless, for the convenience of the ionospheric modeling, the effective height is commonly fixed. For example, $350 \mathrm{~km}$ is applied to the wide area augmentation system [9], and $450 \mathrm{~km}$ is applied to global ionospheric maps (GIMs) [12]. However, what stands in the way of working with a fixed effective ionospheric height is the fact that the ionosphere is not homogeneous. The effective height varies as a function of location, time, and levels of solar activity. For this reason, we harness an ionospheric varying height (IVH) MF instead of a fixed height to reduce the mapping errors.

Using varying height to model the ionosphere is not new. Leitinger et al. [13] applied a latitudedependent mean height to capture the latitude gradient. They found that moving $50 \mathrm{~km}$ higher than the height of the peak density yielded a reasonable height compared with their simulated data. Mushini et al. [14] used the varying height from ionosonde data. Komjathy and Langley [15] showed that the integral height changed up to $150 \mathrm{~km}$ between day and night using international reference ionosphere (IRI). They found a difference of up to 1 TECU between the fixed height of $400 \mathrm{~km}$ and varying heights. Nevertheless, combined satellite and receiver DCBs were estimated instead of separating satellite and receiver DCBs. What is more, the research was conducted in the early twenties, and the ionospheric observables can be further improved using uncombined precise point positioning (UPPP) [16,17].

Applying the latest IRI 2016 version and the improved ionospheric observables based on the UPPP model, therefore, we are able to get more accurate ionospheric observables to evaluate mapping errors and quantify how the IVH impacts ionospheric modeling and DCB estimation. In the second part, we review and examine five types of MFs and their differences in a whole picture for interested readers. In the third part, we explain how to apply varying height. We investigate both the height of the maximum electron density and integral height. With these two varying heights in hand, we model the ionosphere to separate the DCBs from the ionosphere. Then we compare their differences in the Results and Discussion section. We provide the summaries and conclusions in the last part.

\section{Overview of Existing MFs}

The STEC is the integration of electron density along the propagation path. By discretizing the line-of-sight STEC between a receiver and transmitter (Hernández-Pajares et al. 2011), STEC can be expressed as Equation (1).

$$
\text { STEC }=\int_{\mathrm{r}}^{\mathrm{s}} \mathrm{N}_{\mathrm{e}} \times \mathrm{ds}=\sum_{\mathrm{i}=1}^{\mathrm{n}}\left(\mathrm{N}_{\mathrm{e}}\right)_{\mathrm{i}} \delta \mathrm{s}_{\mathrm{i}}=\sum_{\mathrm{i}=1}^{\mathrm{n}} \frac{\left(\mathrm{N}_{\mathrm{e}}\right)_{\mathrm{i}} \delta \mathrm{d}_{\mathrm{i}}}{\frac{\delta \mathrm{d}_{\mathrm{i}}}{\delta \mathrm{s}_{\mathrm{i}}}}=\sum_{\mathrm{i}=1}^{\mathrm{n}} \frac{\delta \mathrm{V}_{\mathrm{i}}}{\cos \mathrm{z}_{\mathrm{i}}^{\prime}}=\sum_{\mathrm{i}=1}^{\mathrm{n}} \mathrm{M}_{\mathrm{i}} \delta \mathrm{V}_{\mathrm{i}}
$$

where STEC is the slant TEC; $\mathrm{s}$ and $\mathrm{r}$ represent the satellite and receiver; $\mathrm{N}_{\mathrm{e}}$ is the electron density; $\mathrm{ds}$ is the element of line-of-sight distance; $\mathrm{n}$ is the number of discretized layers and $\mathrm{i}$ is one of the layers; $\delta s_{i}$ and $\delta d_{i}$ are the slant and vertical height element of $i^{\text {th }}$ layer or shell; $z_{i}^{\prime}$ is the zenith distance at ionospheric pierce point (IPP) of $\mathrm{i}^{\text {th }}$ layer; $\delta \mathrm{V}_{\mathrm{i}}$ is the vertical electron content of $\mathrm{i}^{\text {th }}$ layer; $\mathrm{M}_{\mathrm{i}}$ is the MF of the $\mathrm{i}^{\text {th }}$ layer. 
With $\mathrm{n}=1$, the ionospheric electrons are condensed to a single spherical shell with an infinitesimal thickness. The scheme of the ionosphere SLM is illustrated in Figure 1. Based on the law of sines between the zenith angle $\mathrm{z}^{\prime}$ at IPP and $\mathrm{z}$ at a station as Equation (2), the simplified MF is derived as Equation (3).

$$
\begin{gathered}
\frac{\sin \mathrm{z}^{\prime}}{\mathrm{R}_{\mathrm{e}}}=\frac{\sin \mathrm{z}}{\mathrm{R}_{\mathrm{e}}+\mathrm{H}_{\mathrm{ion}}} \\
\mathrm{MF}=\frac{\mathrm{s}}{\mathrm{d}}=\frac{1}{\cos \mathrm{z}^{\prime}}=1 / \sqrt{1-\sin ^{2} \mathrm{z}^{\prime}}=1 / \sqrt{1-\left(\frac{\mathrm{R}_{\mathrm{e}}}{\mathrm{R}_{\mathrm{e}}+\mathrm{H}_{\text {ion }}} \sin (\mathrm{z})\right)^{2}}=1 / \sqrt{1-\left(\frac{\mathrm{R}_{\mathrm{e}}}{\mathrm{R}_{\mathrm{e}}+\mathrm{H}_{\mathrm{ion}}} \cos (\mathrm{El})\right)^{2}}
\end{gathered}
$$

where $\mathrm{R}_{\mathrm{e}}$ is the radius of the earth (about $6371 \mathrm{~km}$ ); $\mathrm{H}_{\mathrm{ion}}$ is the effective height of the SLM; $\mathrm{z}$ is the zenith distance at stations along the line of sights; $\mathrm{El}$ is the elevation at a receiver station.

The MF has been extensively investigated in ionospheric modeling. Below, major existing MFs and assumptions behind each MF are summarized.

(1) Fixed height MF. This is the simplest and most commonly used. One example is the broadcast model used in GPS [18], as shown in Equation (4). Later, Schaer [19] modified the SLM MF to approximate the extended slab model from the Jet Propulsion Laboratory (JPL) by scaling the zenith angle, as shown in Equation (5).

$$
\begin{gathered}
\mathrm{MF}=1+2 \times\left(\frac{\mathrm{z}+6}{96}\right)^{3} \\
\mathrm{MF}=\frac{1}{\cos \left(\mathrm{z}^{\prime}\right)}=\frac{1}{\sqrt{1-\left(\frac{\mathrm{R}_{\mathrm{e}}}{\mathrm{R}_{\mathrm{e}}+\mathrm{H}_{\mathrm{ion}}}\right)^{2} \sin ^{2}(\alpha \mathrm{z})}}
\end{gathered}
$$

where $\alpha$ is a coefficient of zenith angle that is recommended as 0.9782 with a height of $506.7 \mathrm{~km}$.

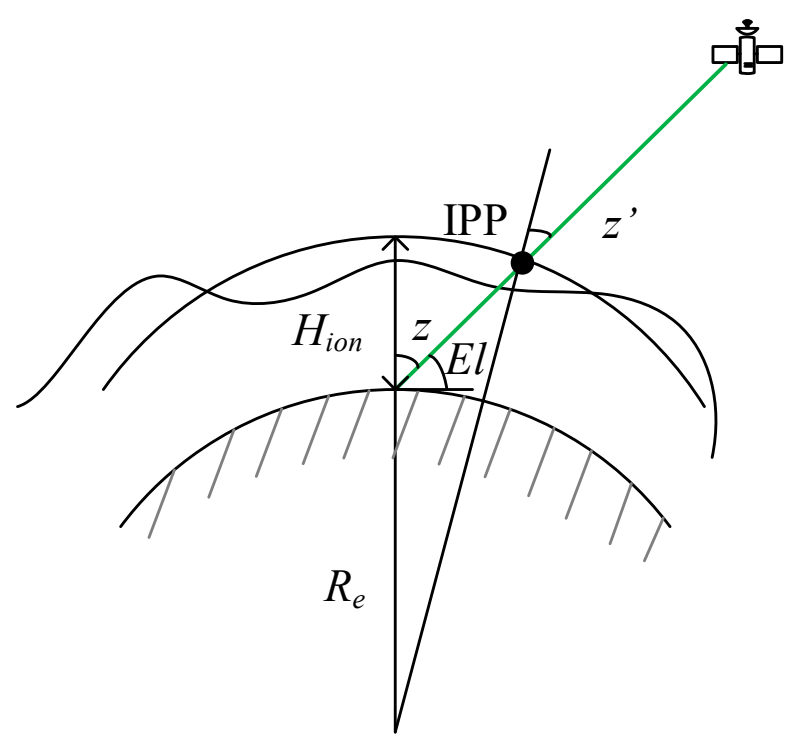

Figure 1. Scheme of the ionosphere single-layer model. The varying line around the fixed height denotes the varying height of the ionosphere. The $\mathrm{H}_{\mathrm{ion}}$ is the assumed heights of the single-layer model (SLM). El and $\mathrm{z}$ are the elevation and zenithal distance or angle. The ionospheric pierce point (IPP) is the intersection of propagation path and the layer. $z^{\prime}$ is the angle distance at IPP.

(2) MF that assumes the ionosphere as a spherical shell with homogeneous thickness. Coster et al. [20] first studied an extended slab model, and the model was adopted by JPL to reproduce the GIMs [1]. Smith et al. [21] summarized the expression of the spherical shell model with a homogeneous density distribution of electrons. The MF for the spherical shell model with thickness is given in Equation (6), for reference. More terms related to thickness can be seen than in the SLM of 
Equation (3). The authors held that not considering the thickness, the MF can be overestimated by up to $15 \%$ at the pierce point zenith angle of $70^{\circ}$.

$$
\mathrm{MF}=\frac{1}{\cos \left(\mathrm{z}^{\prime}\right)}+\frac{\cos ^{2}\left(\mathrm{z}^{\prime}\right)-1}{8 \mathrm{r}_{\mathrm{s}}^{2} \cos ^{5}\left(\mathrm{z}^{\prime}\right)} \mathrm{d}^{2}+\frac{7-10 \cos ^{2}\left(\mathrm{z}^{\prime}\right)+3 \cos ^{4}\left(\mathrm{z}^{\prime}\right)}{128 \mathrm{r}_{\mathrm{s}}^{4} \cos ^{9}\left(\mathrm{z}^{\prime}\right)} \mathrm{d}^{4}+\ldots
$$

where $d$ is the height of assumed thickness and $r_{s}$ is the shell radius at the middle.

(3) GNSS data derived MF. Birch et al. [9] proposed to obtain the height using GNSS data, calculating the inclination rate between zenithal and slant observations, and they concluded 600-1200 km was preferable. Clynch et al. [22] recommended a polynomial MF from least-square to fit TEC ratios by assuming a homogeneous distribution, as Equation (7) shows below. It is also known as Q-factor MF [19]. Jin et al. [23] claimed that the neglect of plasmasphere contribution is the main reason leading to the mapping errors, and they suggested an empirical height, which is equal to the height of maximum density of the F2 layer (HmF2) plus $450 \mathrm{~km}$ for the year of 2006.

$$
M F=a_{0}+a_{1} \times x^{2}+a_{2} \times x^{4}+a_{3} \times x^{6}
$$

where $\mathrm{x}=\frac{2 \mathrm{z}}{\pi} ; \mathrm{a}_{0}=1.0206 ; \mathrm{a}_{1}=0.4663, \mathrm{a}_{2}=3.5055, \mathrm{a}_{3}=-1.8415$.

(4) MF based on empirical models, such as the IRI model, the Chapman profile, and three-dimensional (3D) models. These models are applied to calculate the average height of electron density or the integral height along the trace $[24,25]$. For example, the Chapman function is written as Equation (8).

$$
\mathrm{N}_{\mathrm{e}}=\mathrm{N}_{\mathrm{e}, 0} \mathrm{e}^{0.5\left(1-\mathrm{z}-\mathrm{e}^{-\mathrm{z}}\right)}, \quad \mathrm{z}=\frac{\mathrm{h}-\mathrm{h}_{0}}{\Delta \mathrm{h}}
$$

where $\mathrm{N}_{\mathrm{e}}$ is the electron density when $\mathrm{z}=0$; $\mathrm{h}$ is the height; $\mathrm{h}_{0}$ is the reference height of maximum ion production when the Sun is overhead; $\Delta \mathrm{h}$ is the scale height. With $\mathrm{h}_{0}$ at $350 \mathrm{~km}$ and the scale height $\Delta \mathrm{h}$ of $100 \mathrm{~km}$, the integral height is at $473 \mathrm{~km}$.

Based on a 3D model, Smith et al. [21] introduced a modified MF to minimize the mapping errors, as given in Equation (9).

$$
\mathrm{MF}=\frac{1}{\cos \left(\mathrm{z}^{\prime}\right) \times(1-(\mathrm{p} / 100))}
$$

where $p$ is the percent error and $p$ depends on elevation and effective height.

(5) Varying height MF model. As the main drive of the ionosphere, the solar activities have an obvious cycle. For example, the electron contents at noon are larger than that at midnight. Conversely, the height in the noon is lower than the height at night. As mentioned in the introduction, Komjathy and Langley [15] showed that the integral height changes up to $150 \mathrm{~km}$ between day and night using the IRI 90. Similarly, Mushini et al. [14] investigated the varying height from ionosonde. Leitinger et al. [13] proposed a latitude-dependent variable mean height to consider the latitude gradient.

We display a selection of the five MFs in Figure 2. The left plot displays the MFs as a function of elevation. It can be seen that the MFs range from 1 to 3.5 and they are monotonically decreasing as a function of the elevation. Looking at the SLM at $350 \mathrm{~km}$ and $450 \mathrm{~km}$, we see the lower the fixed height and elevation are, the larger is the MF. In order to see their differences, the relative deviation with reference to the $450 \mathrm{~km}$ is shown in the right Figure 2. It can be seen that Q-factor and US-TEC MFs have a tiny system bias at the elevation of $90^{\circ}$ due to the function fitting. The Klobuchar and Q-factor reveal a fluctuation of elevation and are slightly smaller than the mapping function of $450 \mathrm{~km}$. Other MFs are larger than the reference of $450 \mathrm{~km}$. The mapping differences between the SLM of heights $350 \mathrm{~km}$ and $450 \mathrm{~km}$ are up to $10 \%$ at an elevation mask of $10^{\circ}$. 

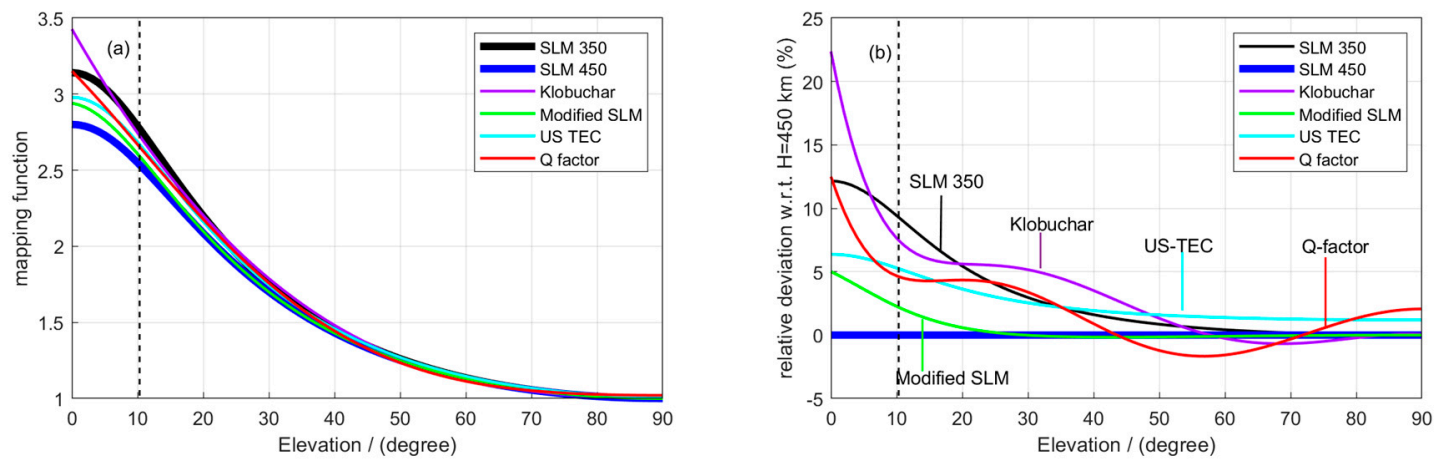

Figure 2. Mapping Functions (MFs) against elevation (a). The relative deviation with reference to SLM-450 (b).

\section{MF with Ionospheric Varying Height (IVH)}

This section explains how to calculate varying height, how to evaluate mapping errors, and how to model the ionosphere to separate the ionospheric TEC from DCBs. We assessed both the HmF2 and the integral height because no agreement was reached on choosing which height in the community.

\subsection{IVH from the IRI 2016 Model}

The IVH from the latest IRI 2016 was employed. The IRI model assimilates data from ionosondes, the incoherent scatter radars, the ISIS and Alouette topside sounders, and in situ instruments on many satellites and rockets. We downloaded the software package online (http://irimodel.org/). As an analytic model, the IRI model provides the median or average value of the HmF2, electron density, and other parameters depending on the location, time, and date.

The numerical integral height from $65 \mathrm{~km}$ to $2000 \mathrm{~km}$ with a stepwise of $2 \mathrm{~km}$ was obtained as Equation (10).

$$
\mathrm{H}_{\text {integral }}=\frac{\int \mathrm{N}_{\mathrm{e}}(\mathrm{h}) \mathrm{hdh}}{\int \mathrm{N}_{\mathrm{e}}(\mathrm{h}) \mathrm{dh}}
$$

where $\mathrm{N}_{\mathrm{e}}(\mathrm{h})$ is the electron density at different height, and dh represents the height element.

We produced the IVH hourly over a station, and applied the linear interpolation to obtain the height at a different time, as input for the ionospheric modeling. Figure 3 shows the ionospheric density profile of a station called PRDS at a local time 14:00 to illustrate the differences between the $\mathrm{HmF} 2$ and the integral height. The HmF2 in red square was around $300 \mathrm{~km}$, while the integral height in blue was about $400 \mathrm{~km}$.

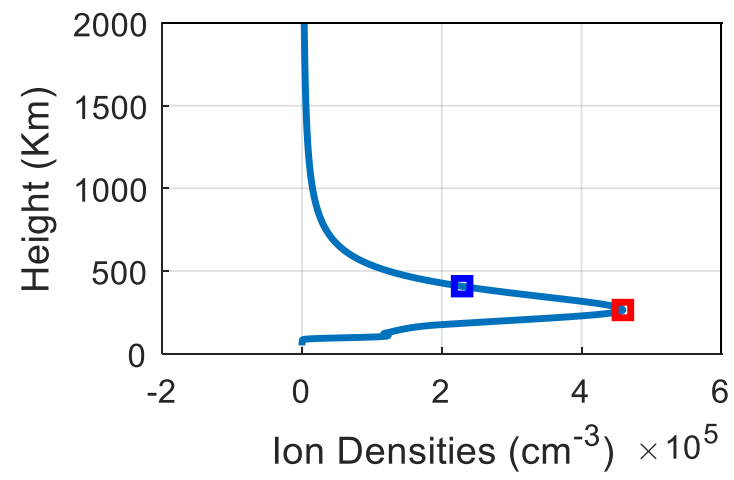

Figure 3. Ionospheric density profile on a station called PRDS $\left(50.87^{\circ} \mathrm{N},-114.29^{\circ} \mathrm{W}\right)$ at local time 14:00 from international reference ionosphere (IRI) 2016. The red square is the HmF2, and the blue is the integral height. 


\subsection{Evaluation of Mapping Errors}

It is challenging to evaluate mapping errors due to a lack of the truth. Niranjan et al., Zhong et al., and Li et al. [25-27] applied either the modeled regional or global VTEC as "ground truth" to assess the mapping errors by deducting the projected VTEC from the "ground truth". However, the "ground truth" is affected by the modeling errors and the fixed height that is applied to derive the model. To avoid these, we adopted the CPP method used by Radicella et al., Komjathy et al., and Nava et al. [10,28,29]. Two CPPs refer to close points at the same time as when the latitude and longitude are close enough by meeting the requirements as Equation (11).

$$
\left\{\begin{array}{cl}
\left|\varphi_{\text {ipp1 }}-\varphi_{\text {ipp2 }}\right| & <0.2^{0} \\
\left|\frac{\lambda_{\text {ipp1 }}}{\cos \left(\varphi_{\text {ipp1 } 1}\right)}-\frac{\lambda_{\text {ipp2 }}}{\cos \left(\varphi_{\text {ipp } 2}\right)}\right| & <0.2^{0}
\end{array}\right.
$$

where the $\varphi_{\text {ipp1 }}$ and $\varphi_{\text {ipp2 }}$ are the latitude of two IPPs; $\lambda_{\text {ipp1 }}$ and $\lambda_{\text {ipp2 }}$ are the longitude of the IPP.

The VTEC of the two CPPs after DCB calibration should theoretically be close under the assumption of the SLM. If the VTEC of the two CPPs is unequal, the errors are considered to be caused by mapping errors ignoring the small region disturbance. The mapping errors denote the absolute differences between the two CPPs, i.e., $\triangle V T E C=\left|V T E C_{1}-V T E C_{2}\right|$. The mapping errors are used to evaluate the mapping performance. As the mapping errors increased with the decrease of elevation, we think the mapping errors were mainly caused by the data with a lower elevation. Note that the CPP method is also affected by the accuracy of DCBs, because the satellite and receiver DCBs are needed to calibrate STEC.

\subsection{Strategies for Ionospheric Modeling}

Ionospheric modeling has been studied since the late twentieth century [1]. Table 1 briefly summarizes the strategies and assumptions of SLM ionospheric modeling. The ionospheric observables from the UPPP model are adopted to reduce the leveling errors when using the smoothed-code method $[16,17]$.

To separate the ionosphere from the biases in the ionospheric observables, an MF converts the STEC into VTEC, and the VTEC is then modeled as a generalized trigonometric series function (GTSF) [30] as Equation (12). The advantage of the GTSF is that GTSF uses two-dimensional polynomial function and finite Fourier series to describe the daily variation of the ionosphere.

$$
\begin{aligned}
\overline{\mathrm{I}}_{1, \mathrm{UPPP}} & =\mathrm{I}_{1}+\frac{1}{\gamma_{2}-1}\left(\mathrm{DCB}^{\mathrm{s}}-\mathrm{DCB}^{\mathrm{r}}\right)+\varepsilon_{\Phi} \\
& =\operatorname{MF}^{\circ} \times \frac{40.3}{\mathrm{f}_{1}^{2}} \times \operatorname{VTEC}\left(\varphi_{\mathrm{iPP}}, \lambda_{\mathrm{iPP}}\right)+\frac{1}{\gamma_{2}-1}\left(\mathrm{DCB}^{\mathrm{s}}-\mathrm{DCB}^{\mathrm{r}}\right)+\varepsilon_{\Phi}
\end{aligned}
$$

where $\operatorname{VTEC}_{\mathrm{k}}\left(\varphi_{\text {IPP }}, \lambda_{\text {IPP }}\right)$ is the vertical TEC; $f_{1}$ is the frequency at $\mathrm{L} 1$ signal; $\gamma_{2}$ is equal to $\mathrm{f}_{1}^{2} / \mathrm{f}_{2}^{2}$; the VTEC is modeled as a GTSF function of latitude and local time; $\varphi_{\text {IPP }}, \lambda_{\text {IPP }}$ are latitude and longitude of the IPP; $\mathrm{DCB}^{\mathrm{s}}, \mathrm{DCB}^{\mathrm{r}}$ are the DCBs of satellites and receivers.

It is worth noting that a different height changes not only the MFs but also the IPP location. The IPP location can be computed as Equation (13). 


$$
\left\{\begin{array}{l}
\varphi_{\mathrm{iPP}}=\arcsin \left(\sin \left(\varphi_{\mathrm{r}}\right) \times \cos (\Delta \mathrm{z})+\cos \left(\varphi_{\mathrm{r}}\right) \times \sin (\Delta \mathrm{z}) \times \cos (\mathrm{Az})\right) \\
\lambda_{\mathrm{iPP}}=\lambda_{\mathrm{r}}+\arcsin \left(\frac{\sin (\Delta \mathrm{z}) \cdot \sin (\mathrm{Az})}{\cos \left(\varphi_{\mathrm{iPP}}\right)}\right)
\end{array}\right.
$$

where the $\varphi_{\text {ipp }}$ and $\lambda_{\text {ipp }}$ are the latitude and longitude of IPP; $\Delta z=z-z^{\prime} ; \varphi_{r}, \lambda_{r}$ are the latitude and longitude of the receiver location; $\mathrm{Az}$ is the azimuth angle.

A height difference of $100 \mathrm{~km}$ would cause severe variations of IPP at a lower elevation of $10^{\circ}$. Therefore, when the IVH is applied, the MF, IPP locations, and zenith angles need to be recalculated accordingly.

Table 1. Technical specifications and strategies of the ionospheric modeling and differential code biases (DCB) determination.

\begin{tabular}{cc}
\hline Strategies & Ionospheric Modeling \\
\hline $\begin{array}{c}\text { Ionospheric model function at a station } \\
\text { Elevation cut-off } \\
\text { Coordinate frame } \\
\text { Height }\end{array}$ & General Triangle Series Function (GTSF) \\
$20^{\circ}$ & $\begin{array}{c}\text { Geographic frame } \\
\text { Satellite and receiver DCB separation } \\
\text { Assumptions }\end{array}$ \\
& $\begin{array}{c}\text { Ionospheric varying height (IVH) from the IRI 2016 model } \\
\text { Zero-mean reference of all available satellites } \\
\text { The ionospheric electron content is condensed in an } \\
\text { infinitesimal thickness layer, and an MF converts the slant total } \\
\text { electron content (STEC) into the vertical total electron } \\
\text { content (VTEC) }\end{array}$ \\
& The biases are assumed to be a constant during a day. \\
\hline
\end{tabular}

\section{Results and Discussion}

In this section, we start to describe the experiment setup. We then show results of IVH from the IRI model. Finally, results and discussions of IVH effects on mapping errors, VTEC, and satellite and receiver DCBs are explained.

\subsection{Data Description}

Data of two weeks from 8 March to 21 March 2015 in Western Canada and South America were selected to evaluate mapping errors. These stations are shown in blue circles in Figure 4. Besides, the geographic distribution of the 14 stations was selected to estimate DCBs shown in Figure 4 . As Li et al. [3] put that seven stations can estimate satellite DCBs accurately at $0.1 \mathrm{~ns}, 14$ global stations were chosen to calculate DCBs here. In addition, quiet and disturbed GPS observations from the internation GNSS service (IGS) were selected to evaluate the performance of ionospheric modeling. The ionospheric quiet and storm days are 16 March 2015 and 17 March 2015. The Dst index on March 16 was $20 \mathrm{nT}$, and contrastingly, the Dst reached $-220 \mathrm{nT}$ on March 17 [31]. In addition, the K index on 16 and 17 March 2015 are shown in Figure 5. The K index ranged from zero to nine, corresponding to from minor to extreme storms. In Figure 5, index over four are in red. We can say March 17 was under ionospheric disturbance due to small Dst and high $\mathrm{K}$ index, while March 16 was ionospheric quiet. UPPP was applied to calculate ionospheric observables. For the UPPP processing strategies, please refer to [32]. 


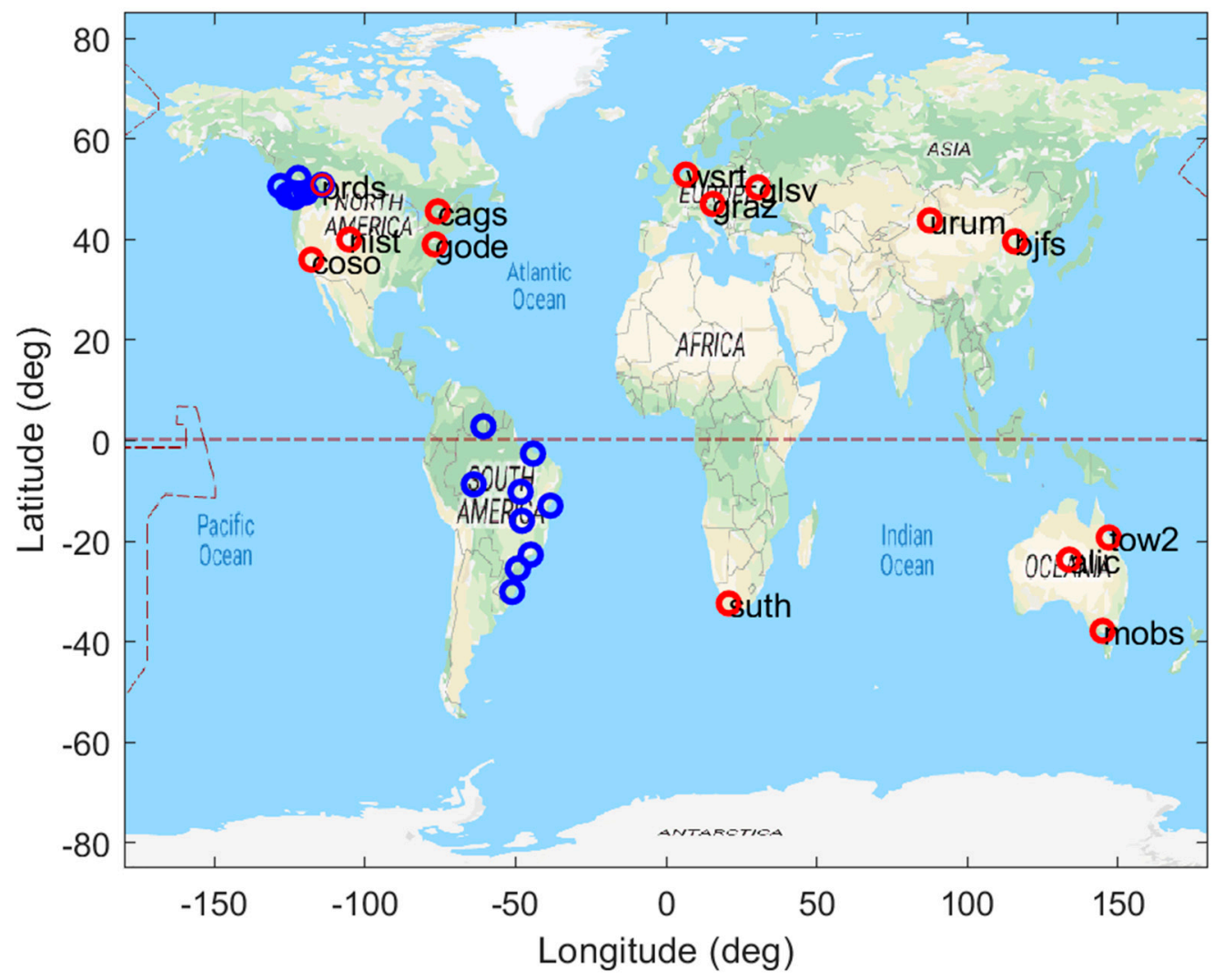

Figure 4. Geographic distribution of the 14 processed stations in red circles were used to estimate satellite and receiver DCBs. Two regions of Western Canada and South America in blue circles were selected to evaluate mapping errors.
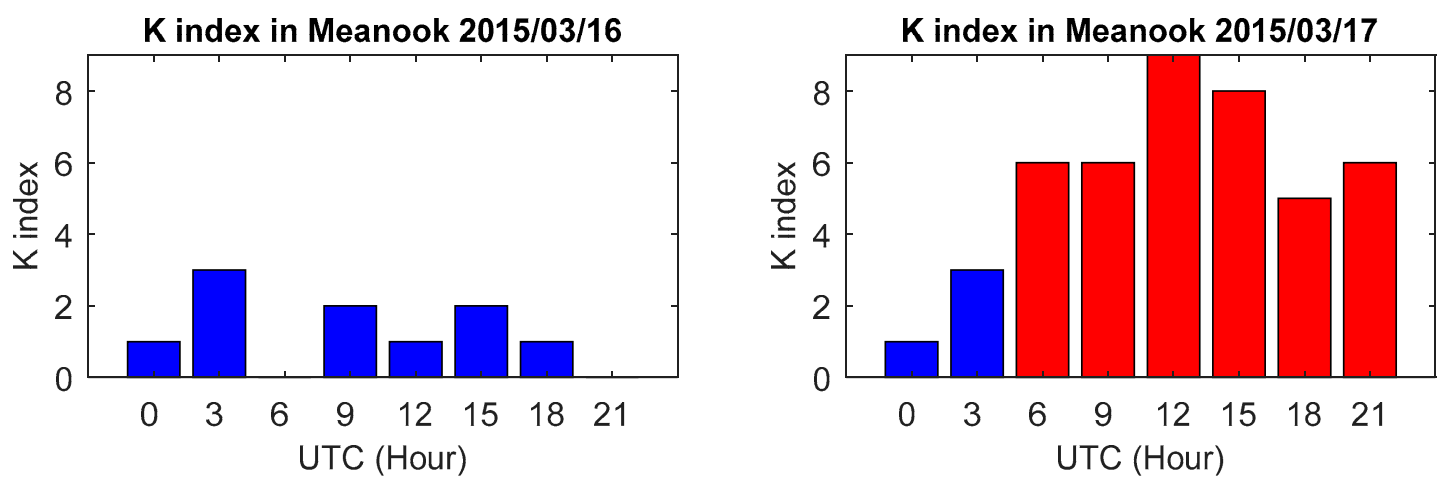

Figure 5. K index on March 16 and 17, 2015 in Meanook $\left(54.62^{\circ} \mathrm{N}, 246.65^{\circ} \mathrm{E}\right)$.

\subsection{IVH from the IRI 2016 Model}

As mentioned previously, the IRI 2016 model was applied to produce the station-specific HmF2 and numerical integral height. Figure 6a shows the variation of the HmF2 (below) and numerical integral height (upper) with local time on March 17 for these 14 global stations. We present only the height on March 17 because the IRI model is a median model (i.e., a monthly average model).

A clear daily variation of the height can be observed on the Figure 6a. The integral height tended to increase during the night and decrease in the daytime. The HmF2 showed a similar trend. We also display the height differences between $\mathrm{HmF} 2$ and the integral height on the Figure $6 \mathrm{~b}$. The differences were at about $150 \mathrm{~km}$ for most stations, and the differences were not a constant. 
The varying height depends on the electron density distribution. During the intense solar activity, for example, at noon, the number of electrons in the F layer is significantly more than that in the plasmasphere. The average height will be around the height of maximum density in the F layer. During the weak solar activity, say, at midnight, the ions distribute sparsely. The average height will be above the height of maximum density in the F layer. In general, the height under intense solar activity is lower than that in the weak [33].
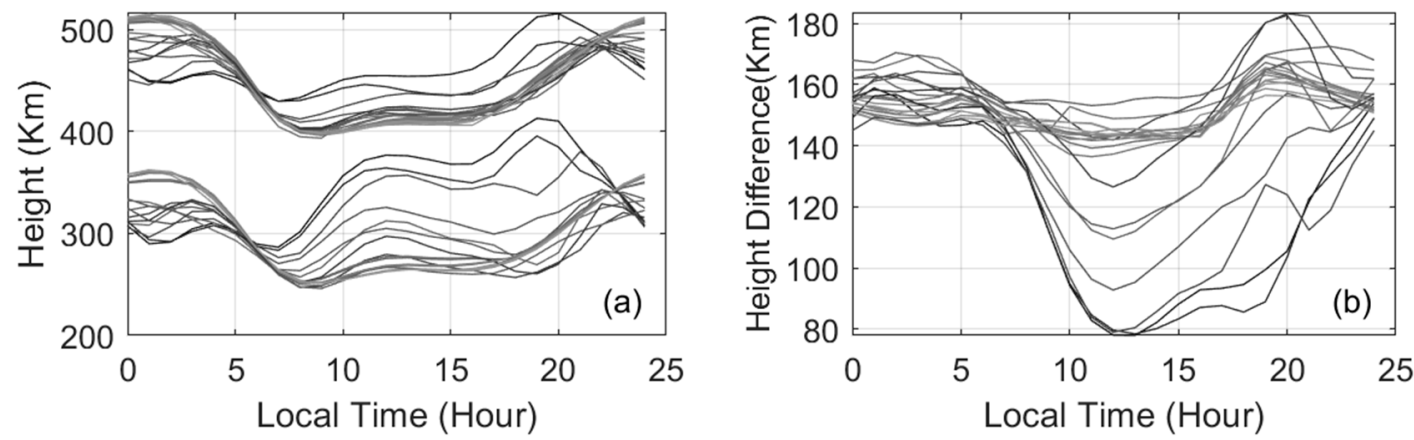

Figure 6. On (a), station-specific and daily variation of the HmF2 (below) and the numerical integral height (upper) using the IRI 2016 model against the local time. The differences between the integral height and the HmF2 are on (b).

\subsection{IVH Impacts on Mapping Errors}

Figure 7 presents the mapping errors against the lower elevation of two CPPs for two regions of South America and Western Canada. The left column is for South America, and the right column is for Western Canada. It can be seen that the mapping errors in Western Canada were about six times smaller than those of South America. This is because at the lower latitude larger ionospheric gradients caused larger mapping errors. Comparing the heights, we can see that mapping errors using integral height were smaller than those using the fixed height of $450 \mathrm{~km}$. The enhancement is about $9.4 \%$ in Western Canada, and $7.4 \%$ in South America when we use root mean square as criteria. However, mapping errors using HmF2 presented a different scale in Western Canada (7.5\%) and South America $(37.5 \%)$. We can see that the HmF2 generate smaller mapping errors at low latitude and the integral height has smaller mapping errors at middle latitude.

If we compare the number of the CPPs from these three heights, we notice more pairs of CPPs were observed when the height was lower. As shown in the previous subsection of the height from the IRI model, the HmF2 was around $300 \mathrm{~km}$, and the integral height was sometimes larger than $450 \mathrm{~km}$ and sometimes smaller than $450 \mathrm{~km}$. Therefore, the number of CPPs was the most when using the varying height of $\mathrm{HmF} 2$.

We also discovered the challenge of evaluating the MF is using the same IPP pairs. Due to the change of the IPPs, we could not control the same coinciding IPPs. When we tried to control the same IPPs, the number of the CPPs was significantly reduced and most of them were for higher elevation, which was within 0.1 TECU and not helpful. 

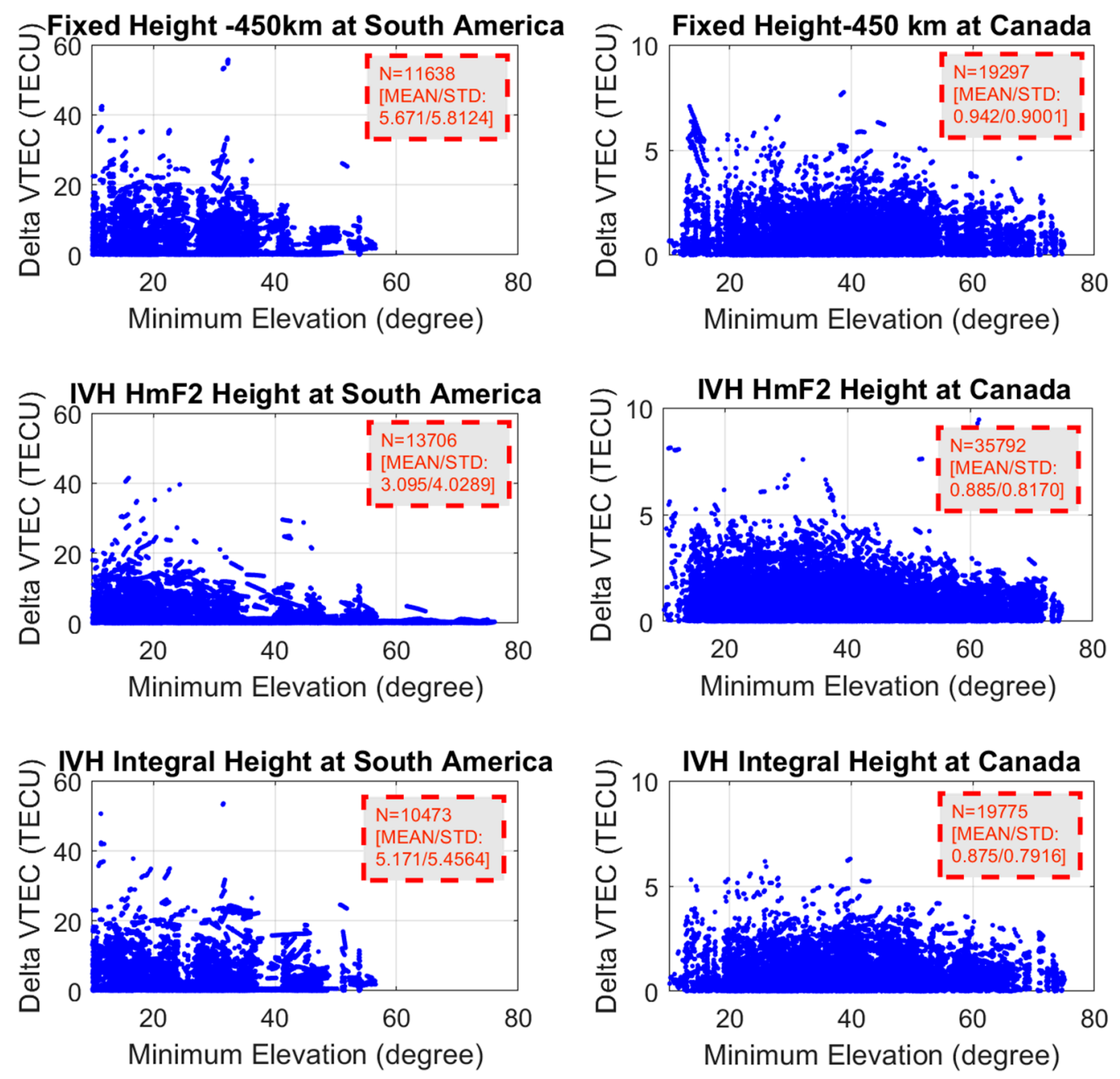

Figure 7. The mapping errors against the lower elevation in the South America and Western Canada. $N$ is the total number of coinciding pierce points.

\subsection{IVH Impacts on Ionospheric Modeling}

UPPP is the state-of-the-art method to reduce leveling errors [17]. Ionospheric observables from the two stations using the UPPP model on March 16 and 17, 2015 are shown in Figure 8. That the ionospheric observables on March 17 fluctuated due to the disturbance can be seen from UTC 10 to 20 .
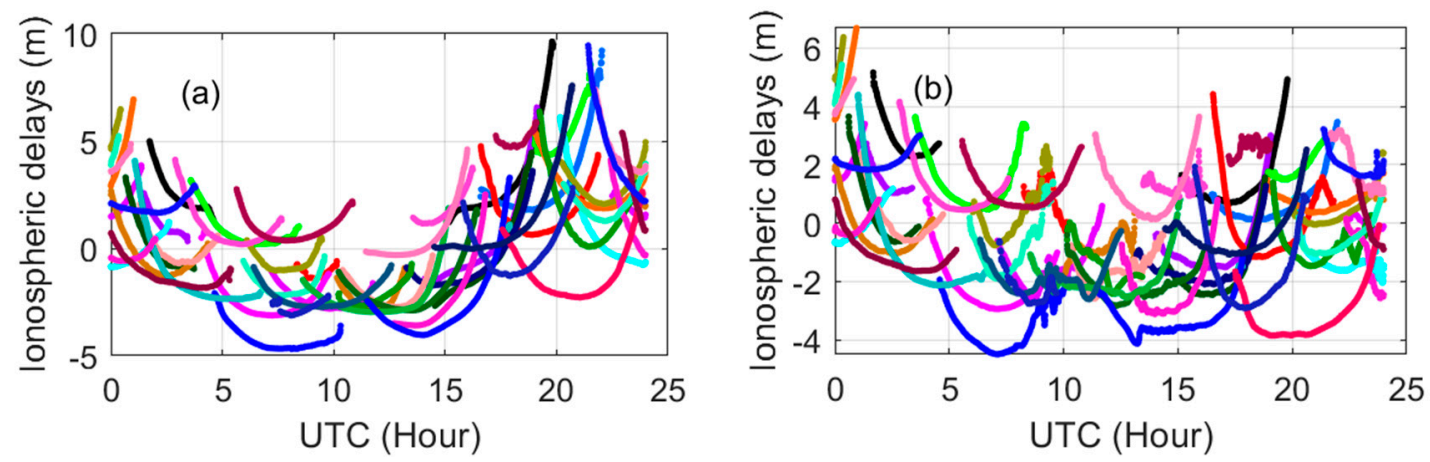

Figure 8. Ionospheric observables using the uncombined precise point positioning (UPPP) model on March 16 (a) and 17 (b), 2015. The ionospheric observables from a satellite correspond to one color. 


\subsubsection{IVH Effects on VTEC}

We obtain VTEC using ionospheric modeling with different varying height. Figure 9 displays the VTEC over station ALBH using these three types of heights on the left $(a, c)$, and the right $(b, d)$ is the corresponding differences with reference to the fixed height of $450 \mathrm{~km}$ (SLM450). Generally, a similar trend was found for the three types of heights on both days. In addition, the disturbance on March 17 from UTC 10:00 until the end of the day is reflected in the low left figure. We can see the differences on March 16 are generally larger than those on March 17 on the right side.

For the HmF2, the differences were up to 2.5 TECU on March 16, and 1.8 TECU on March 17. VTEC computing from the fixed height is always larger than that from the HmF2. This is related to the heights, of which HmF2 is lower than the fixed height of $450 \mathrm{~km}$. The lower the altitude is, the larger zenithal angle is. A larger zenithal angle means a larger MF, based on equation (3). With a larger MF, a smaller VTEC is needed to maintain the same STEC. Therefore, a lower altitude produces smaller VTEC.

For the integral height, the differences between the integral height and SLM450 were within $0.5 \mathrm{TECU}$, significantly smaller than those of the HmF2. And the value could be positive and negative for the integral height on both days.
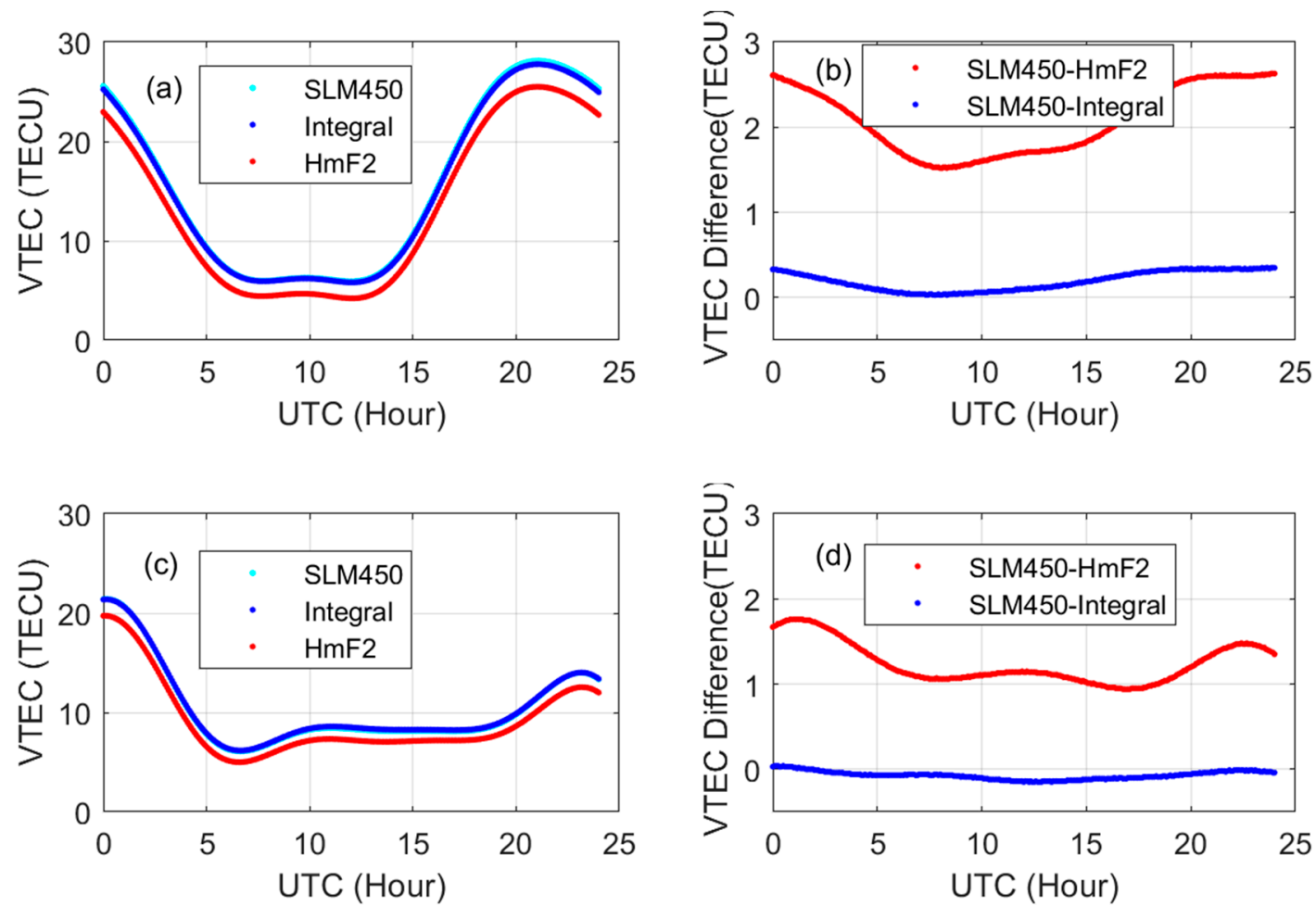

Figure 9. The VTEC variation over station ALBH with fixed height $450 \mathrm{~km}, \mathrm{HmF} 2$, and integral height (left), and the differences with reference to the fixed height $450 \mathrm{~km}$ (right).

\subsubsection{IVH Effects on Satellite and Receiver DCBs}

To examine the magnitude of IVH mapping effects on the satellite and receiver DCBs, we estimated the satellite and receiver DCBs using the 14 global stations mentioned above. We compared the estimated satellite DCB using the fixed height of $450 \mathrm{~km}$ with the IGS products to ensure the external accuracy, as shown in Figure 10. We can see the similar trend and small difference when compared with IGS products. We show only the March 17 due to the similarity of the results. 


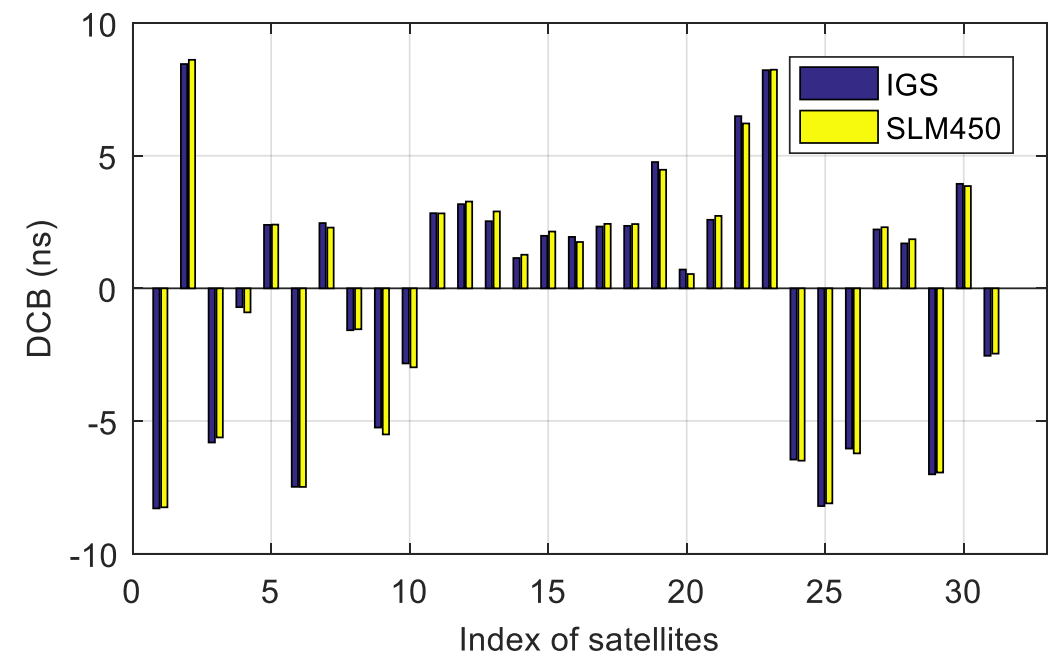

Figure 10. Satellite DCB estimated using the fixed height of $450 \mathrm{~km}$ compared with IGS products on 17 March 2015.

To examine the differences compared with the fixed height, we created the differences between satellite and receiver DCBs from the two IVHs and the fixed height $450 \mathrm{~km}$, as shown in the Figure 11. The quiet day is on the left (a) and (c), and the right (b) and (d) are for the disturbed day. Generally, the differences of DCBs between the HmF2 and the SLM450 were larger than the difference between the integral height.
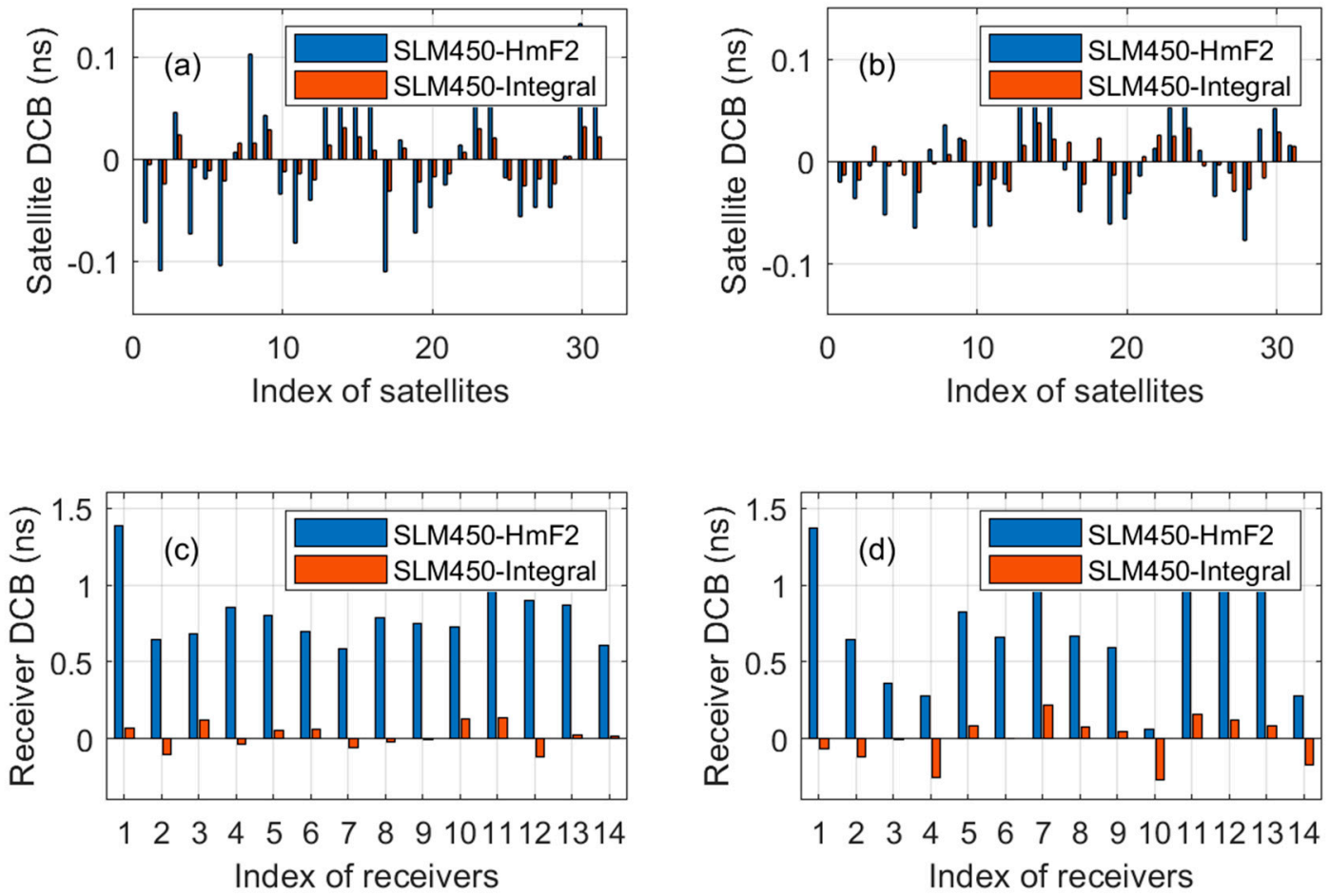

Figure 11. Satellite and receiver DCB differences of $\mathrm{HmF} 2$, and numerical integral height compared with the fixed height $450 \mathrm{~km}$ on $16(\mathbf{a}, \mathbf{c})$ and $17(\mathbf{b}, \mathbf{d})$ March 2015. The blue is DCBs from HmF2 and the yellow is that from the integral height.

For the satellite DCBs in (a) and (b), the differences were within $0.1 \mathrm{~ns}$ for most satellites. Regarding the receiver DCBs in (c) and (d), we can see that the receiver DCBs were not as stable as satellite DCBs, and the differences were ten times larger than with the satellite DCBs. The receiver DCBs from the 
HmF2 exhibited a positive value, which means the receiver DCBs from HmF2 were all smaller than the DCBs based on the fixed height of $450 \mathrm{~km}$.

\section{Conclusions}

Reviewing the development of mapping functions, we propose an MF with the ionospheric varying height to reduce the mapping effects due to inhomogeneous ionosphere. The contributions of the paper include an evaluation of mapping errors using the CPP method for the HmF2 and the integral height MF. Using ionospheric observables based on UPPP, we analyzed impacts of the two IVHs on the ionospheric modeling, satellite and receiver DCB estimation. On the basis of the numerical analysis, we draw the following conclusions:

(1) The integral height and $\mathrm{HmF} 2$ varies about $100 \mathrm{~km}$, with daytime lower, and nighttime higher. The height differences between the integral height and HmF2 were about $150 \mathrm{~km}$.

(2) Compared with using a fixed height of $450 \mathrm{~km}$, the mapping errors using the integral height achieved an $8 \%$ reduction of mapping errors. Interestingly, 35\% smaller mapping errors were found using $\mathrm{HmF} 2$ at the lower latitude.

(3) A higher height produces larger VTEC; lower height smaller VTEC. The modeled VTEC using HmF2 was up to 2.5 TECU smaller when compared with the VTEC using a fixed height of $450 \mathrm{~km}$. By contrast, the difference of VTEC between the integral height and the fixed height was within 0.5 TECU.

(4) The effects of IVH on the satellite DCBs using these three different heights was within $0.1 \mathrm{~ns}$, and larger impact on receiver DCBs were at $1.0 \mathrm{~ns}$. And the impact of HmF2 on receiver DCBs are all positive.

When we applied the diurnal and station-specific IVH, the height may not have been accurate enough to cover a large area. In addition, the research assumes that IRI offers accurate ionospheric density and varying height. However, the IRI model is a median model, and the varying height on the quiet and disturbed days had little differences. We think more accurate varying height may help further reduce mapping errors. In addition, the conclusions should be used with caution due to the limited test in the study.

Author Contributions: Y.X. did literature review, collected data, processed data and prepared the paper draft. Y.G. supervised the research and revised the manuscript.

Funding: The research is funded by the Chinese Scholarship Councile and the University of Calgary.

Acknowledgments: The authors appreciate service provided by the International GNSS Service (IGS) and the International Reference Ionosphere (IRI) model.

Conflicts of Interest: The authors declare no conflict of interest.

\section{References}

1. Mannucci, A.J.; Wilson, B.; Yuan, D. A global mapping technique for GPS-derived ionospheric total electron content measurements. Radio Sci. 1998, 33, 565-582. [CrossRef]

2. Sardón, E.; Zarraoa, N. Estimation of total electron content using GPS data: How stable are the differential satellite and receiver instrumental biases? Radio Sci. 1997, 32, 1899-1910. [CrossRef]

3. Li, Z.; Yuan, Y.; Li, H.; Ou, J.; Huo, X. Two-step method for the determination of the differential code biases of COMPASS satellites. J. Geod. 2012, 86, 1059-1076. [CrossRef]

4. Nie, Z.; Zhou, P.; Liu, F.; Wang, Z.; Gao, Y. Evaluation of Orbit, Clock and Ionospheric Corrections from Five Currently Available SBAS L1 Services: Methodology and Analysis. Remote Sens. 2019, 11, 411. [CrossRef]

5. Lanyi, G.E.; Roth, T. A comparison of mapped and measured total ionospheric electron content using global positioning system and beacon satellite observations. Radio Sci. 1988, 23, 483-492. [CrossRef]

6. Hernández-Pajares, M.; Juan, J.; Sanz, J.; García-Fernández, M. Towards a More Realistic Ionospheric Mapping Function; XXVIII URSI General Assembly: Delhi, India, 2005. 
7. Brunini, C.; Camilion, E.; Azpilicueta, F. Simulation study of the influence of the ionospheric layer height in the thin layer ionospheric model. J. Geod. 2011, 85, 637-645. [CrossRef]

8. Wang, X.-L.; Wan, Q.-T.; Ma, G.-Y.; Li, J.-H.; Fan, J.-T. The influence of ionospheric thin shell height on TEC retrieval from GPS observation. Res. Astron. Astrophys. 2016, 16, 116. [CrossRef]

9. Birch, M.J.; Hargreaves, J.K.; Bailey, G.J. On the use of an effective ionospheric height in electron content measurement by GPS reception. Radio Sci. 2002, 37. [CrossRef]

10. Nava, B.; Radicella, S.M.; Leitinger, R.; Coïsson, P. Use of total electron content data to analyze ionosphere electron density gradients. Adv. Space Res. 2007, 39, 1292-1297. [CrossRef]

11. Zhao, J.; Zhou, C. On the optimal height of ionospheric shell for single-site TEC estimation. GPS Solut. 2018, 22, 48. [CrossRef]

12. Hernandez-Pajares, M.; Juan, J.M.; Sanz, J.; Orus, R.; Garcia-Rigo, A.; Feltens, J.; Komjathy, A.; Schaer, S.C.; Krankowski, A. The IGS VTEC maps: A reliable source of ionospheric information since 1998. J. Geod. 2009, 83, 263-275. [CrossRef]

13. Leitinger, R.; Spalla, P.; Ciraolo, L. Latitude Dependent Mean Ionospheric Height-A New Approach to the TEC Evaluation from NNSS Data. Acta Geod. Geophys. Hung. 1998, 33, 61-73. [CrossRef]

14. Mushini, S.C.; Jayachandran, P.T.; Langley, R.B.; MacDougall, J.W. Use of varying shell heights derived from ionosonde data in calculating vertical total electron content (TEC) using GPS-New method. Adv. Space Res. 2009, 44, 1309-1313. [CrossRef]

15. Komjathy, A.; Langley, R. The effect of shell height on high precision ionospheric modelling using GPS. In Proceedings of the 1996 IGS Workshop International GPS Service for Geodynamics (IGS), Silver Spring, MD, USA, 19-21 March 1996.

16. Zhang, B.; Ou, J.; Yuan, Y.; Li, Z. Extraction of line-of-sight ionospheric observables from GPS data using precise point positioning. Sci. China Earth Sci. 2012, 55, 1919-1928. [CrossRef]

17. Xiang, Y.; Gao, Y.; Shi, J.; Xu, C. Consistency and analysis of ionospheric observables obtained from three precise point positioning models. J. Geod. 2019, 2019, 1-10. [CrossRef]

18. Klobuchar, J.A. Ionospheric time-delay algorithm for single-frequency GPS users. IEEE Trans. Aerosp. Electron. Syst. AES 1987, 23, 325-331. [CrossRef]

19. Schaer, S. Mapping and Predicting the Earth's Ionosphere Using the Global Positioning System. Ph.D. Thesis, University of Berne, Bern, Switzerland, 1999.

20. Coster, A.J.; Gaposchkin, E.M.; Thornton, L.E. Real-Time Ionospheric Monitoring System Using GPS. Navigation 1992, 39, 191-204. [CrossRef]

21. Smith, D.A.; Araujo-Pradere, E.A.; Minter, C.; Fuller-Rowell, T. A comprehensive evaluation of the errors inherent in the use of a two-dimensional shell for modeling the ionosphere. Radio Sci. 2008, 43, 1-23. [CrossRef]

22. Clynch, J.R.; Coco, D.S.; Coker, C.; Bishop, G.J. A versatile GPS ionospheric monitor-High latitude measurements of TEC and scintillation. In Proceedings of the Institute of Navigation Satellite Division, 2nd International Technical Meeting, Colorado Springs, CO, USA, 27-29 September 1989; pp. 445-450.

23. Wen, J.; Wan, W.; Ding, F.; Yue, X.; She, C.; Liu, L. Experimental observation and statistical analysis of the vertical TEC mapping function. Chin. J. Geophys. 2018, 53, 22-29.

24. Conker, R.S.; El-Arini, M.B. An ionospheric obliquity process responsive to line-of-sight azimuth and elevation. Radio Sci. 2002, 37, 1097. [CrossRef]

25. Zhong, J.; Lei, J.; Dou, X.; Yue, X. Assessment of vertical TEC mapping functions for space-based GNSS observations. GPS Solut. 2016, 20, 353-362. [CrossRef]

26. Niranjan, K.; Srivani, B.; Gopikrishna, S.; Rama Rao, P. Spatial distribution of ionization in the equatorial and low-latitude ionosphere of the Indian sector and its effect on the pierce point altitude for GPS applications during low solar activity periods. J. Geophys. Res. Space Phys. 2007, 112. [CrossRef]

27. Li, M.; Yuan, Y.; Zhang, B.; Wang, N.; Li, Z.; Liu, X.; Zhang, X. Determination of the optimized single-layer ionospheric height for electron content measurements over China. J. Geod. 2018, 92. [CrossRef]

28. Radicella, S.M.; Nava, B.; Coïsson, P.; Kersley, L.; Bailey, G.J. Effects of gradients of the electron density on Earth-space communications. Ann. Geophys. 2004, 47. [CrossRef]

29. Komjathy, A.; Sparks, L.; Mannucci, A.J.; Coster, A. The ionospheric impact of the October 2003 storm event on Wide Area Augmentation System. GPS Solut. 2005, 9, 41-50. [CrossRef] 
30. Yuan, Y.; Ou, J. A generalized trigonometric series function model for determining ionospheric delay. Prog. Nat. Sci. 2004, 14, 1010-1014. [CrossRef]

31. WDC. World Data Center for Geomagnetism. Available online: http://wdc.kugi.kyoto-u.ac.jp/dstdir/ (accessed on 19 November 2017).

32. Xiang, Y.; Gao, Y. Improving DCB Estimation Using Uncombined PPP. Navigation 2017, 64, 463-473. [CrossRef]

33. Memarzadeh, Y. Ionospheric Modeling for Precise GNSS Applications. Ph.D. Thesis, Technische Universiteit Delft, Delft, The Netherlands, 2009. article distributed under the terms and conditions of the Creative Commons Attribution (CC BY) license (http://creativecommons.org/licenses/by/4.0/). 